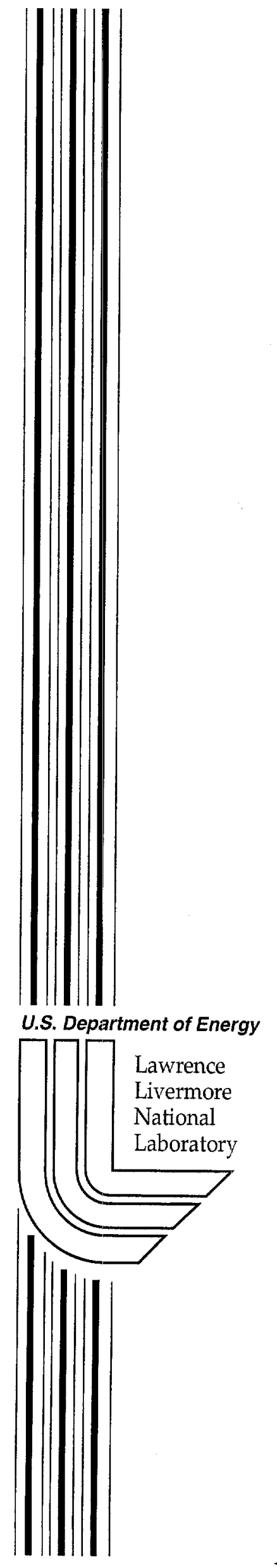

Preprint

UCRL-CR-145536

\title{
Comparison of Machining with Long-Pulse Green and Ultrashort Pulse Lasers
}

\author{
A. E. Wynne, and B. C. Stuart
}

\section{May 18, 2001}




\section{DISCLATMER}

This document was prepared as an account of work sponsored by an agency of the United States Government. Neither the United States Government nor the University of California nor any of their employees, makes any warranty, express or implied, or assumes any legal liability or responsibility for the accuracy, completeness, or usefulness of any information, apparatus, product, or process disclosed, or represents that its use would not infringe privately owned rights. Reference herein to any specific commercial product, process, or service by trade name, trademark, manufacturer, or otherwise, does not necessarily constitute or imply its endorsement, recommendation, or favoring by the United States Government or the University of California. The views and opinions of authors expressed herein do not necessarily state or reflect those of the United States Government or the University of California, and shall not be used for advertising or product endorsement purposes.

This is a preprint of a paper intended for publication in a journal or proceedings. Since changes may be made before publication, this preprint is made available with the understanding that it will not be cited or reproduced without the permission of the author.

This report has been reproduced directly from the best available copy.

Available electronically at http://www.doc.gov/bridge

Available for a processing fee to U.S. Department of Energy

And its contractors in paper from

U.S. Department of Energy

Office of Scientific and Technical Information

P.O. Box 62

Oak Ridge, TN 37831-0062

Telephone: (865) 576-8401

Facsimile: (865) 576-5728

E-mail: reports@adonis.osti.gov

Available for the sale to the public from

U.S. Department of Commerce

National Technical Information Service

5285 Port Royal Road

Springfield, VA 22161

Telephone: (800) 553-6847

Facsimile: (703) 605-6900

E-mail: orders@ntis.fedworld.gov

Online ordering: http://www.ntis.gov/ordering.htm

OR

Lawrence Livermore National Laboratory

Technical Information Department's Digital Library

http://www.llnl.gov/tid/Library.html 


\section{Comparison of Machining with Long-Pulse Green and Ultrashort Pulse Lasers}

Alexis E. Wynne and Brent C. Stuart

Lawrence Livermore National Laboratory

Contract number L8951

May 18, 2001 
Table of Contents

1. Statement of Work 3

2. Experimental Setup 4

3. Measurements 5

4. Plots for 304 Stainless Steel 6

5. Plots for Rhenium 12

6. Plots for Titanium 16

$\begin{array}{ll}\text { 7. Plots for Hastalloy X } & 20\end{array}$

$\begin{array}{ll}\text { 8. Plots for N5 } & 24\end{array}$

9. Plots for Silicon Carbide 27

10. Discussion 31 


\section{Statement of Work}

I) LLNL measured the material removal rate from stainless steel, silicon carbide, rhenium, N5, hastalloy $X$, and titanium as a function of pulse fluence at a wavelength of $810 \mathrm{~nm}$ for pulse durations of $150 \mathrm{fs}, 1.5 \mathrm{ps}, 20 \mathrm{ps}$, and $500 \mathrm{ps}$. The spot size of the beam used was 150 microns in diameter and the nominal material thickness was $1-2 \mathrm{~mm}$. These experiments were performed on the existing $1 \mathrm{kHz}$ laser system. Holes of different penetration depths were obtained to ascertain change in removal rate as a function of depth.

Measurements included electron microscopy of selected samples

II) The experiments in I were repeated for all materials but select pulse durations with the sample in a vacuum of base pressure $10 \mathrm{mTorr}$ to determine if hole quality and ablation rate is improved.

III) LLNL measured material removal rate from stainless steel, silicon carbide, rhenium, $\mathrm{N} 5$, hastalloy $\mathrm{X}$, and titanium as a function of pulse fluence at a wavelength of $532 \mathrm{~nm}$ for pulse duration at $200 \mathrm{~ns}$. The spot size of the beam used was 200 microns in diameter and the material thickness was the same as in task I. Holes of different penetration depths were obtained to ascertain changes in removal rate as a function of depth. 


\section{Experimental Set-Up}

For the first set of experiments, we used a chirped-pulse amplification (CPA) Ti:sapphire laser and regenerative amplifier system. The system delivered pulses at a repetition rate of $1 \mathrm{kHz}$ with energies up to $1.5 \mathrm{~mJ}$ at a wavelength of $810 \mathrm{~nm}$. Because of the CPA configuration, the pulse width could be varied from 150 fs to 20 ps without changing any other parameters. When a 500 ps pulse was needed, the uncompressed pulse was picked off and sent to the drilling chamber.

We used a lens with a focal length of $34 \mathrm{~cm}$ to focus the gaussian beam to a round spot. The part was placed before the beam focus in order to achieve a spot size of 150 micron diameter. We used circular polarization to avoid the uneven drilling effects of static linear polarization. The beam hit the part at normal incidence, and the fluence was changed by adjusting the energy while the spot size remained constant.

The materials used were 304 stainless steel, rhenium, titanium, silicon carbide, hastalloy $\mathrm{X}$, and N5. These coupons were placed in a vacuum chamber that has a system of gas baffles that prevent coating the entrance window with the plasma. Argon was bled in at the baffles while the vacuum pump was on to achieve equilibrium. When drilling in vacuum, the pressure in the chamber was $10 \mathrm{mTorr}$ and the pressure at the entrance window was $400 \mathrm{mT}$ Torr. When drilled in air, the chamber was vented and the lid left off.

A fast mechanical shutter (UniBlitz) was used to select a defined number of pulses. For each fluence and pulse-width chosen, ten holes were drilled, two holes for each of five different time intervals (number of pulses). The times and corresponding number of pulses chosen varied with fluence to achieve similar depths at all fluences. The depths of the two holes for each number of pulses were averaged in each case and used to determine the drilling rate for that number of pulses. For breakthrough detection, an imaging set-up was installed at the rear end of the chamber. A lens imaged the plane of the part onto a CCD. Breakthrough was timed by first detection of light on the camera after the shutter was opened.

For the second set of experiments, a diode pumped, intra-cavity doubled, Ndd:YAG laser was used. This system delivers $200 \mathrm{~ns}$ pulses at a repetition rate of 2 $\mathrm{kHz}$ with energies up to $10 \mathrm{~mJ}$ at a wavelength of $532 \mathrm{~nm}$. A $15 \mathrm{~cm}$ focal length lens was used to focus the gaussian beam to a round spot with a diameter of 200 microns. The part was placed at focus to achieve the smallest possible spot size. The fluence was adjusted by changing the power while the spot size remained constant. The beam hit the part at normal incidence and all holes were drilled in air. The drilling technique was similar to above except that only 6 different fluences were used.

All holes were measured with a Nikon measuring microscope (MM-40) with an encoded $Z$ stage that is connected to a digital read-out (Quadra-Chek 2000). Depths were measured by focusing at the surface of the part, zeroing the read-out, and the focusing at the bottom of the deepest part of the hole. We estimated the error in depth to be +-3 microns. The fluence was determined by measuring the pulse energy with a Coherent 
LM3 power meter and measuring the spot size with Coherent Beam Analyzer software. The error in fluence is determined to be $20 \%$ due to laser energy fluctuations and beam diameter measurement error.

\section{Measurements}

We measured initial ablation rate of all materials as a function of fluence, pulse duration and ambient pressure (air vs. vacuum). In order to calculate the rate curves, a constant depth was chosen for all fluences, and the rate for that depth was plotted against fluence. The depth chosen was between 10 and 20 micron because we noticed that the rate changes dramatically with depth as discussed below.

We measured ablation rate as a function of depth for the $810 \mathrm{~nm}$ cases in order to better understand how the hole progresses. We also measured breakthrough times for given samples of the materials in order to study completion of high aspect ratio holes.

The following data is presented in graphs organized by material. For each material, there are initial ablation rate vs. fluence plots for $810 \mathrm{~nm}$ in air and vacuum, as well as green machining. Following that are rate vs. depth curves for select cases using the $810 \mathrm{~nm}$ laser. And finally there is a breakthrough time vs. fluence curve for all pulsewidths tested using the $810 \mathrm{~nm}$ laser in vacuum and air. 


\section{Stainless Steel}
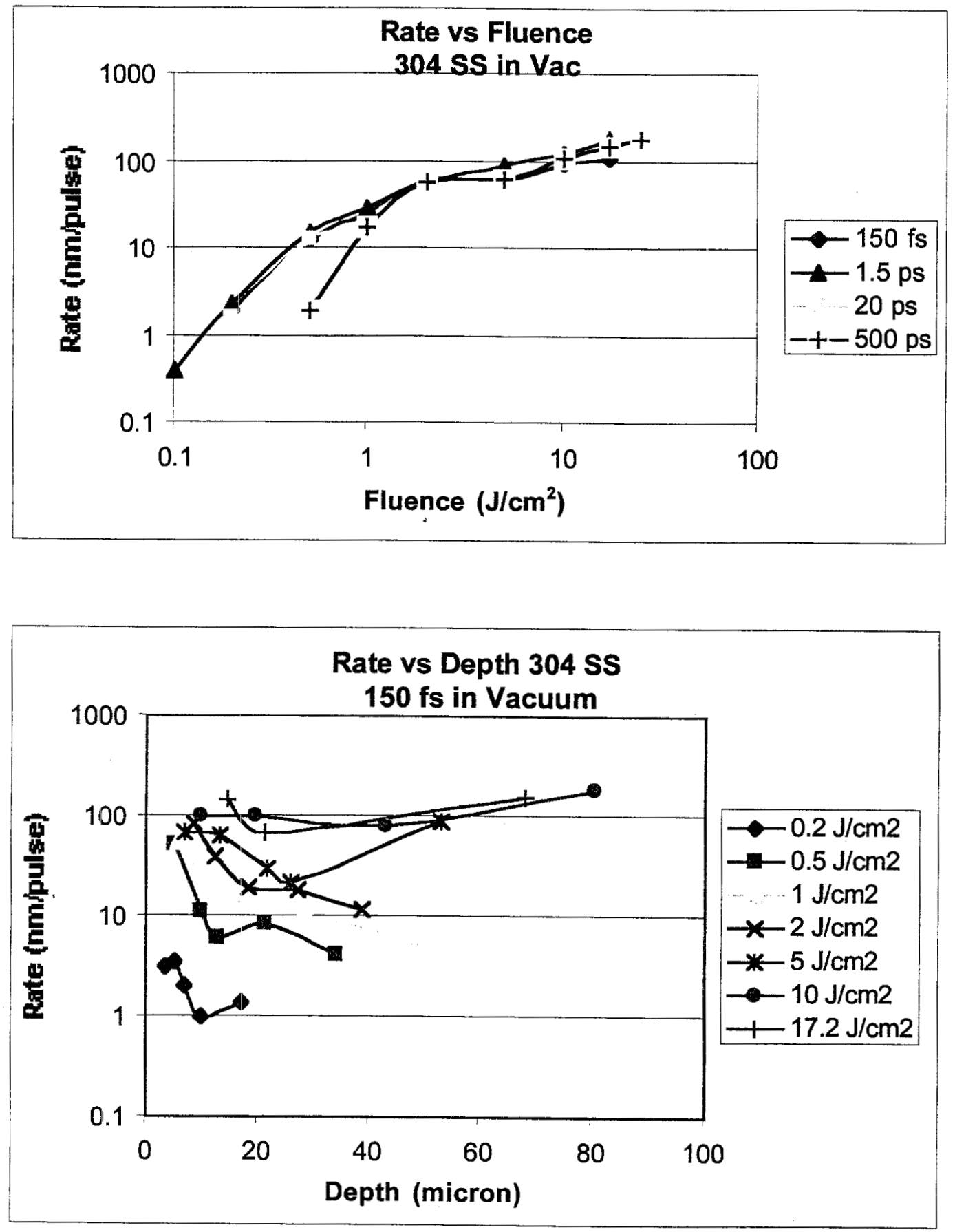

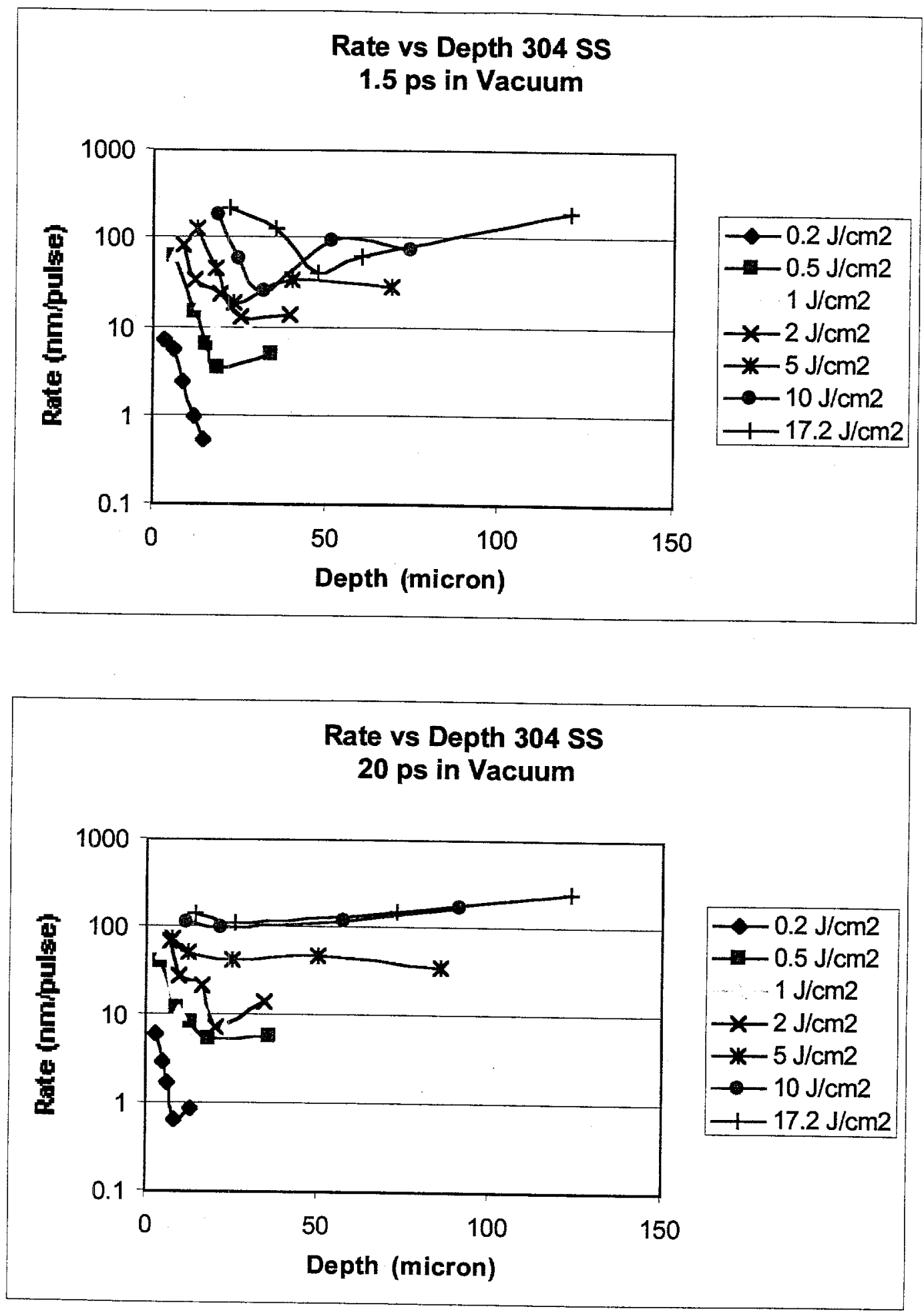

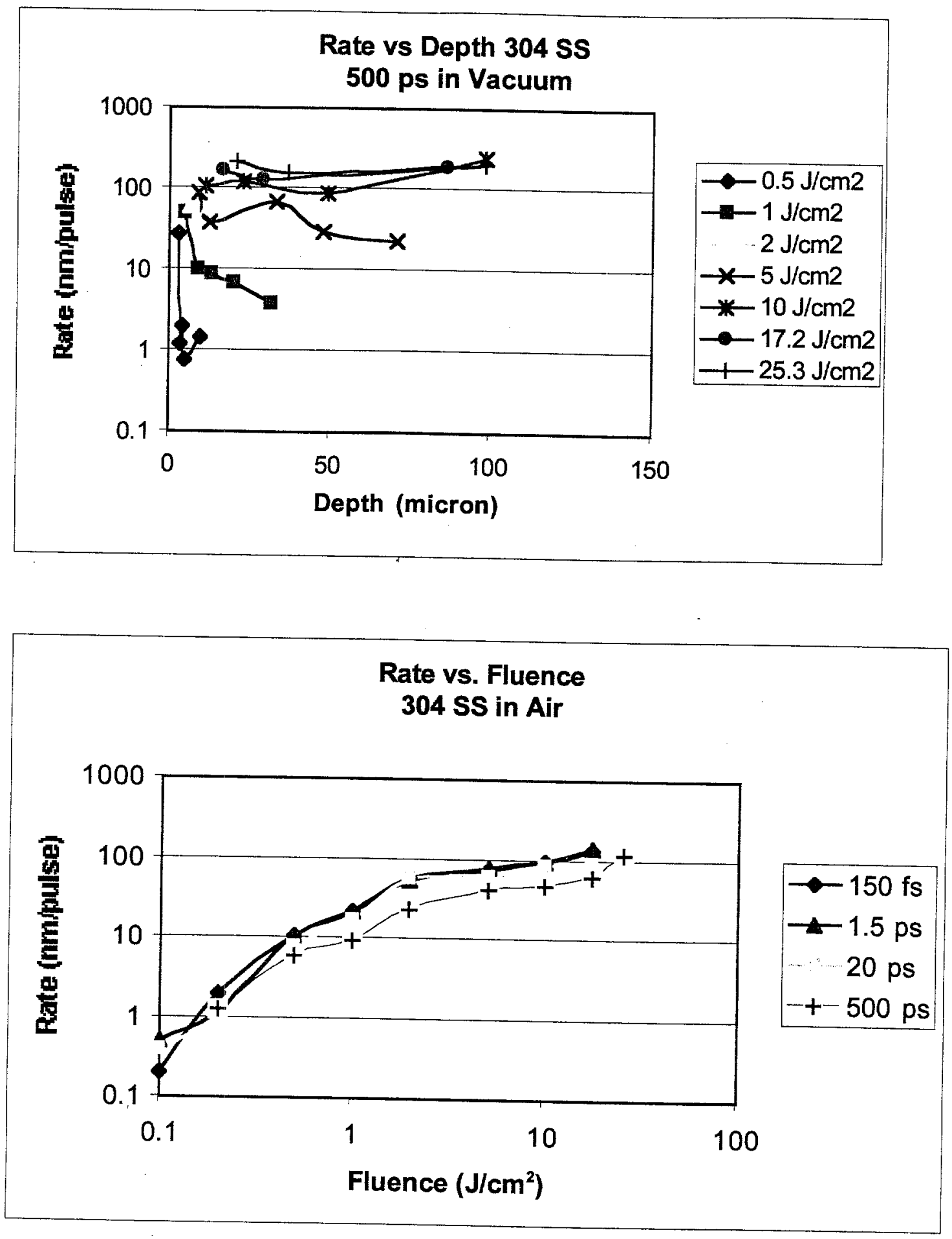

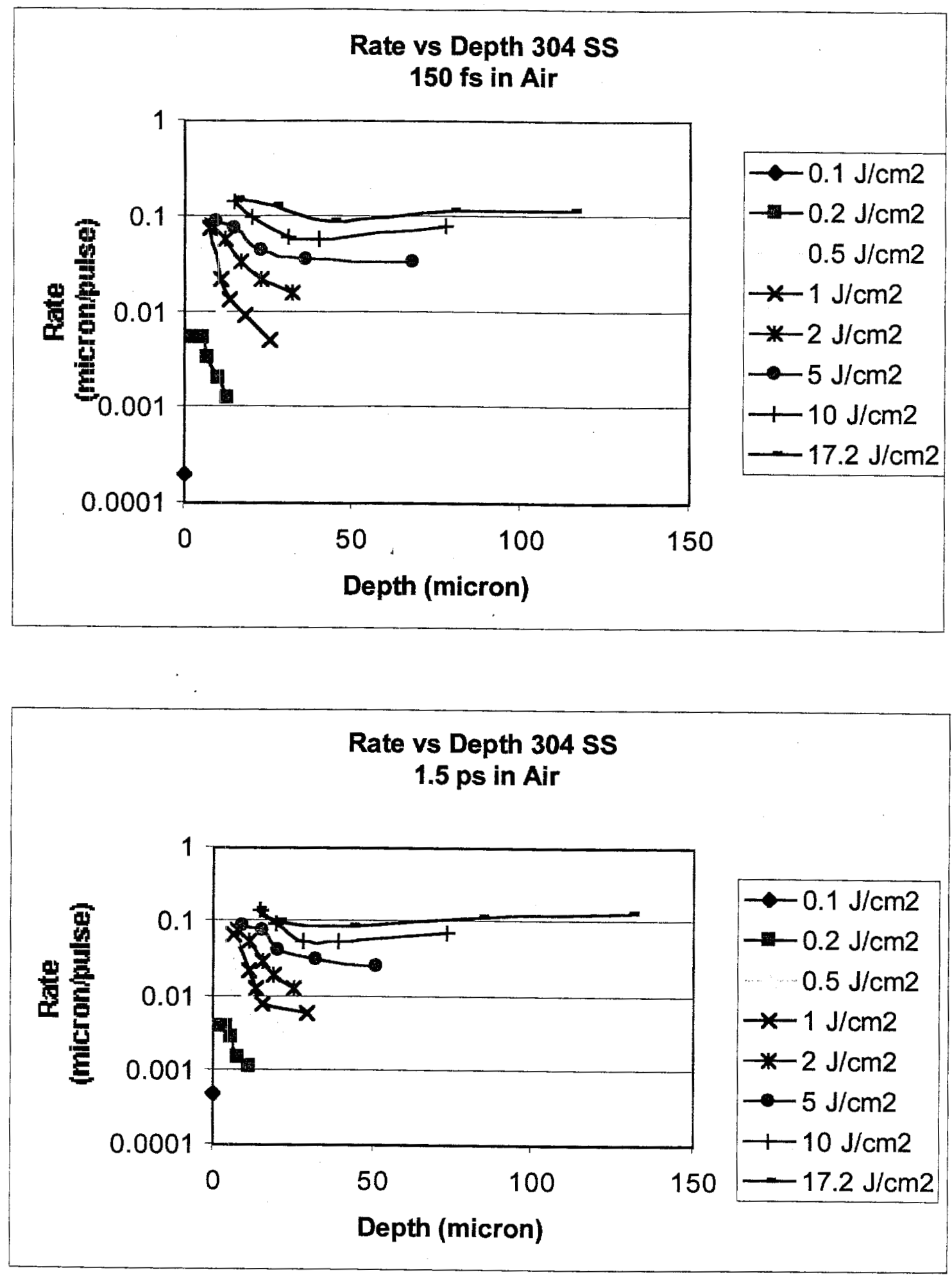

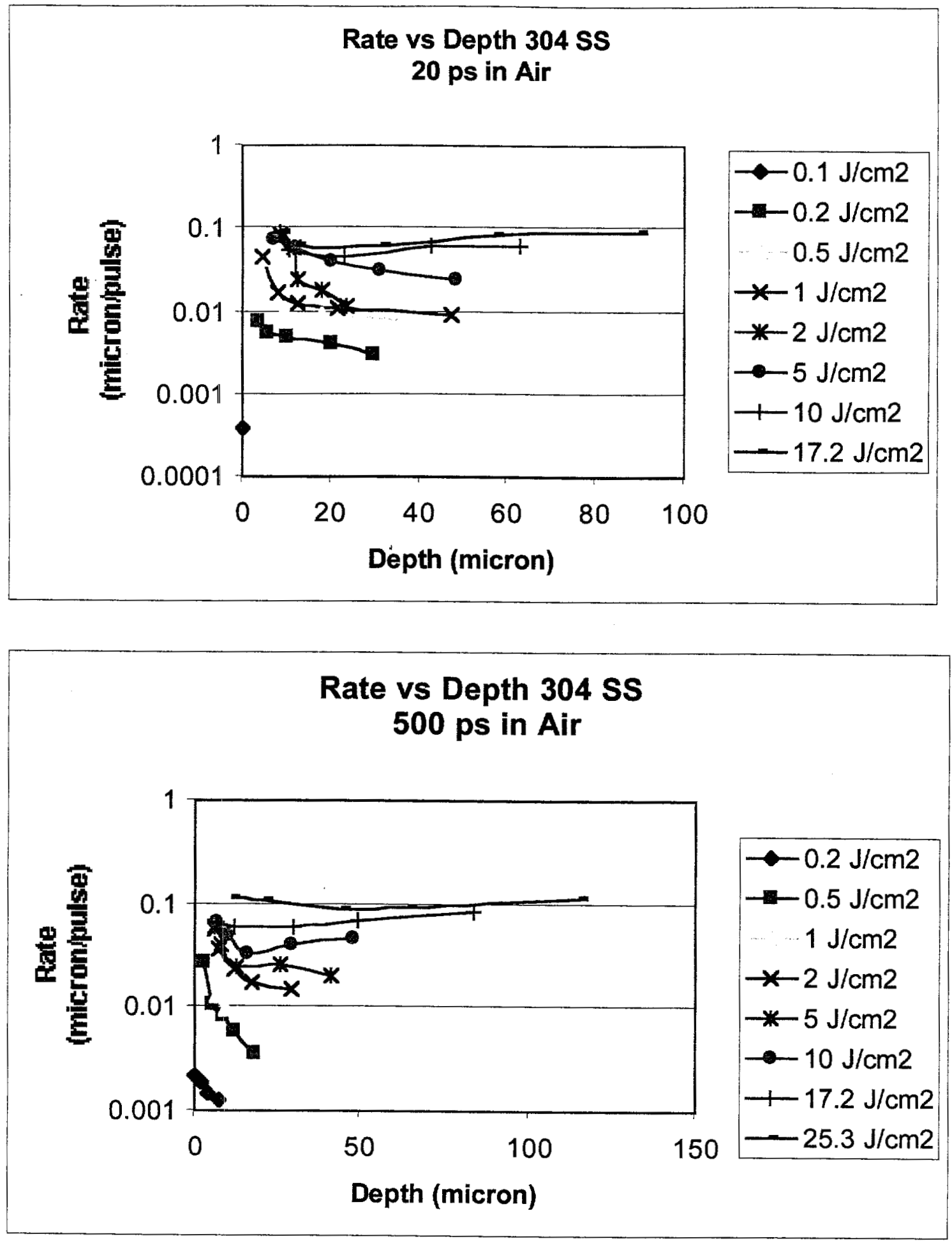

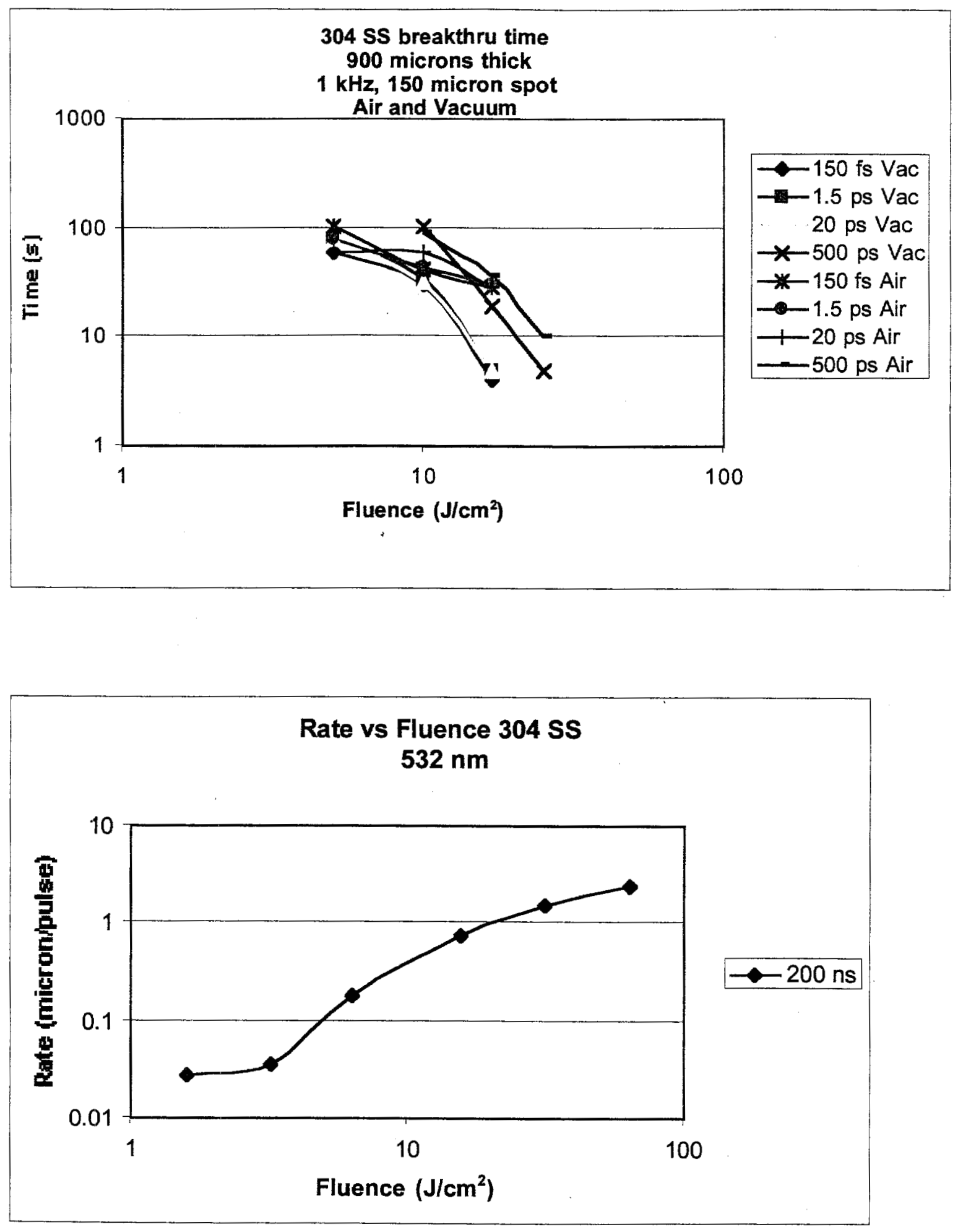


\section{Rhenium}
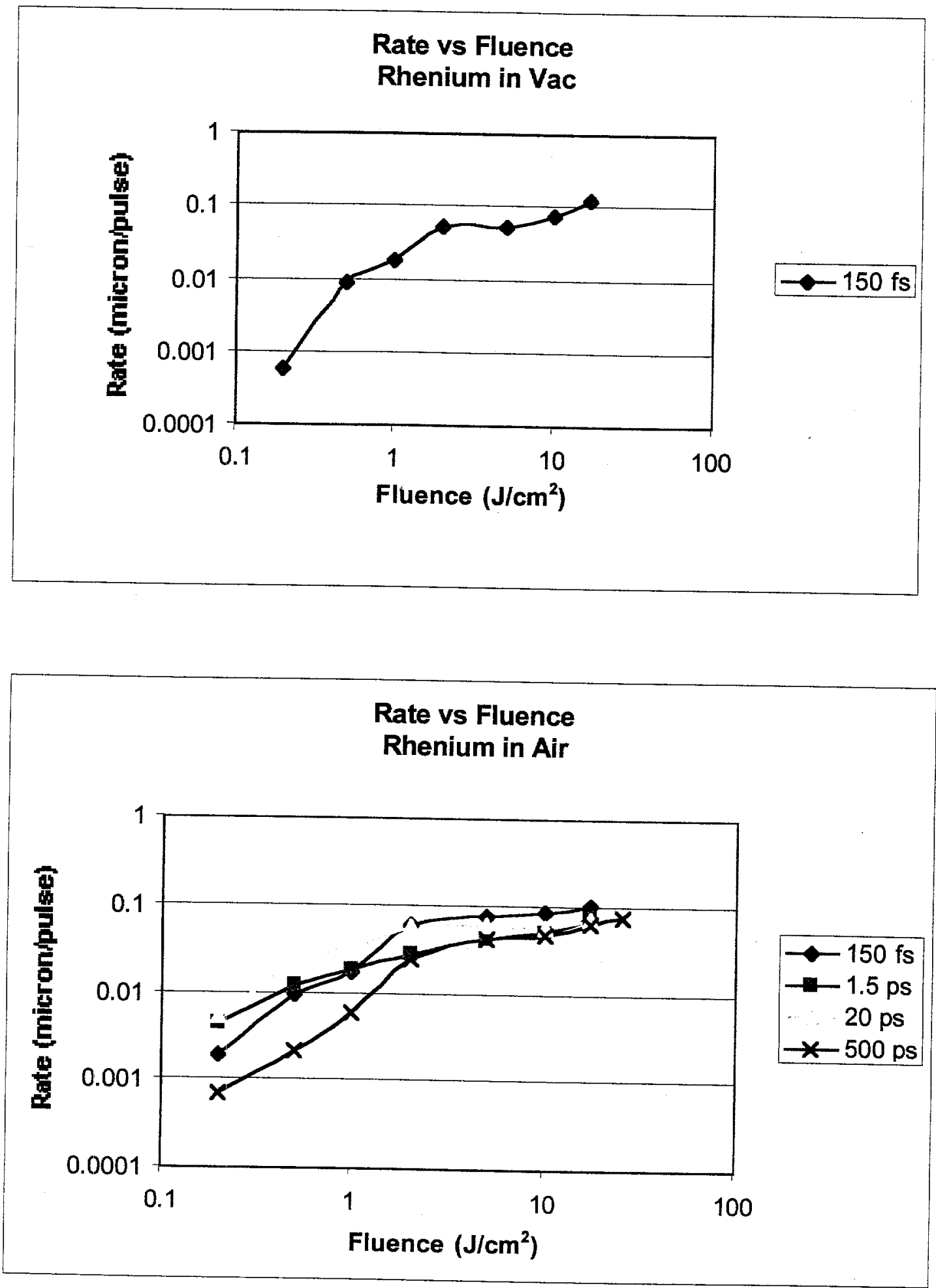

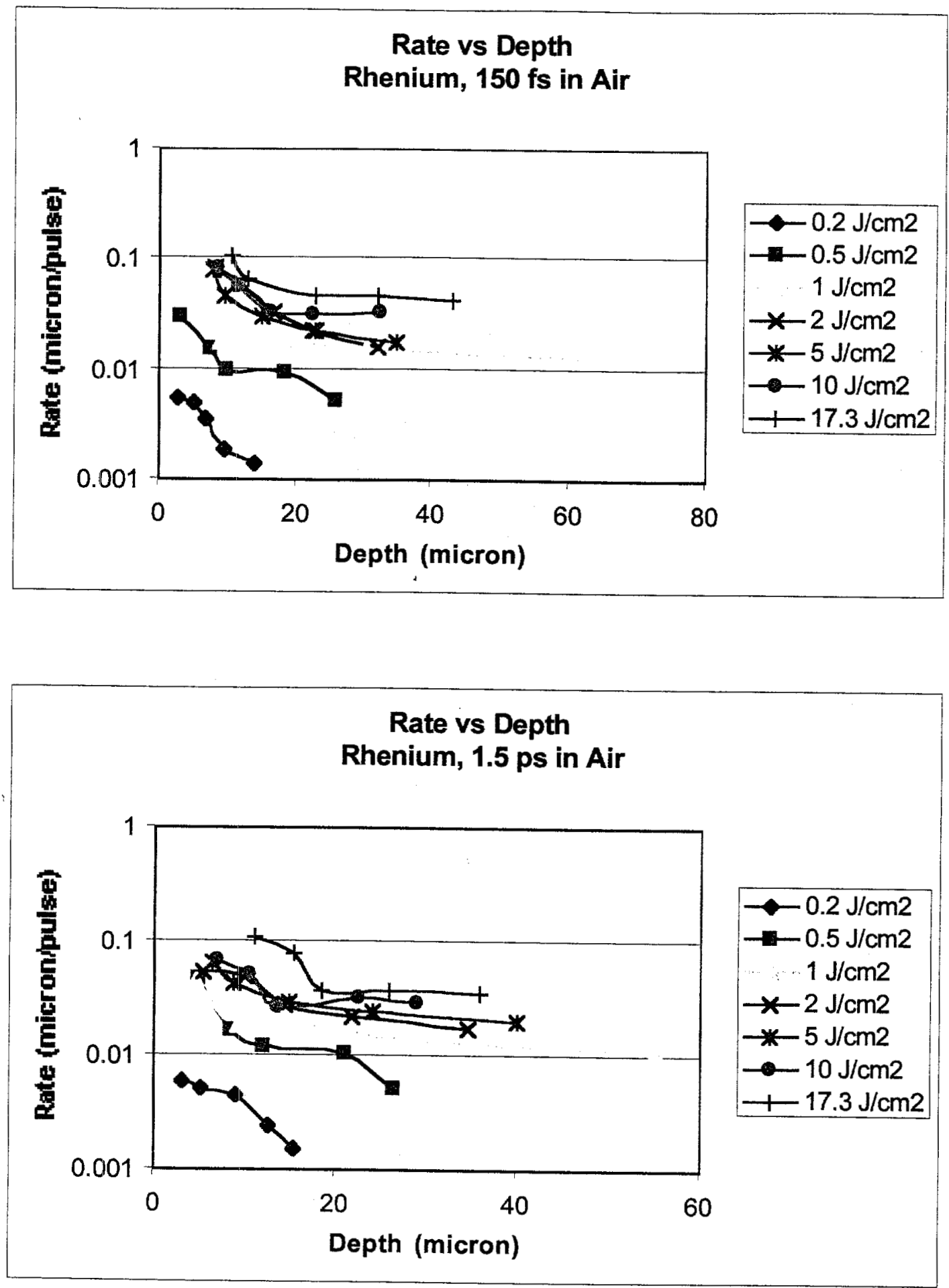

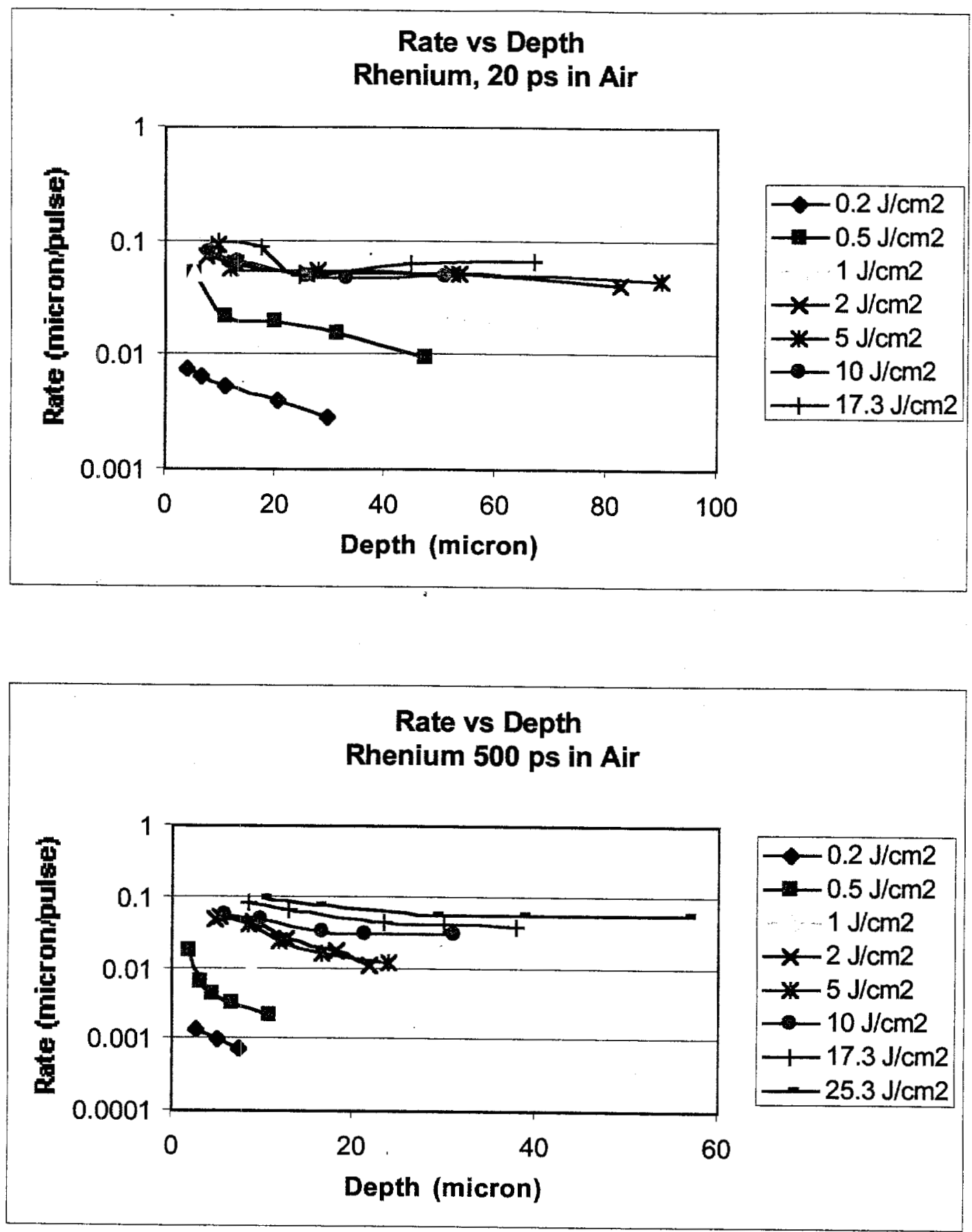


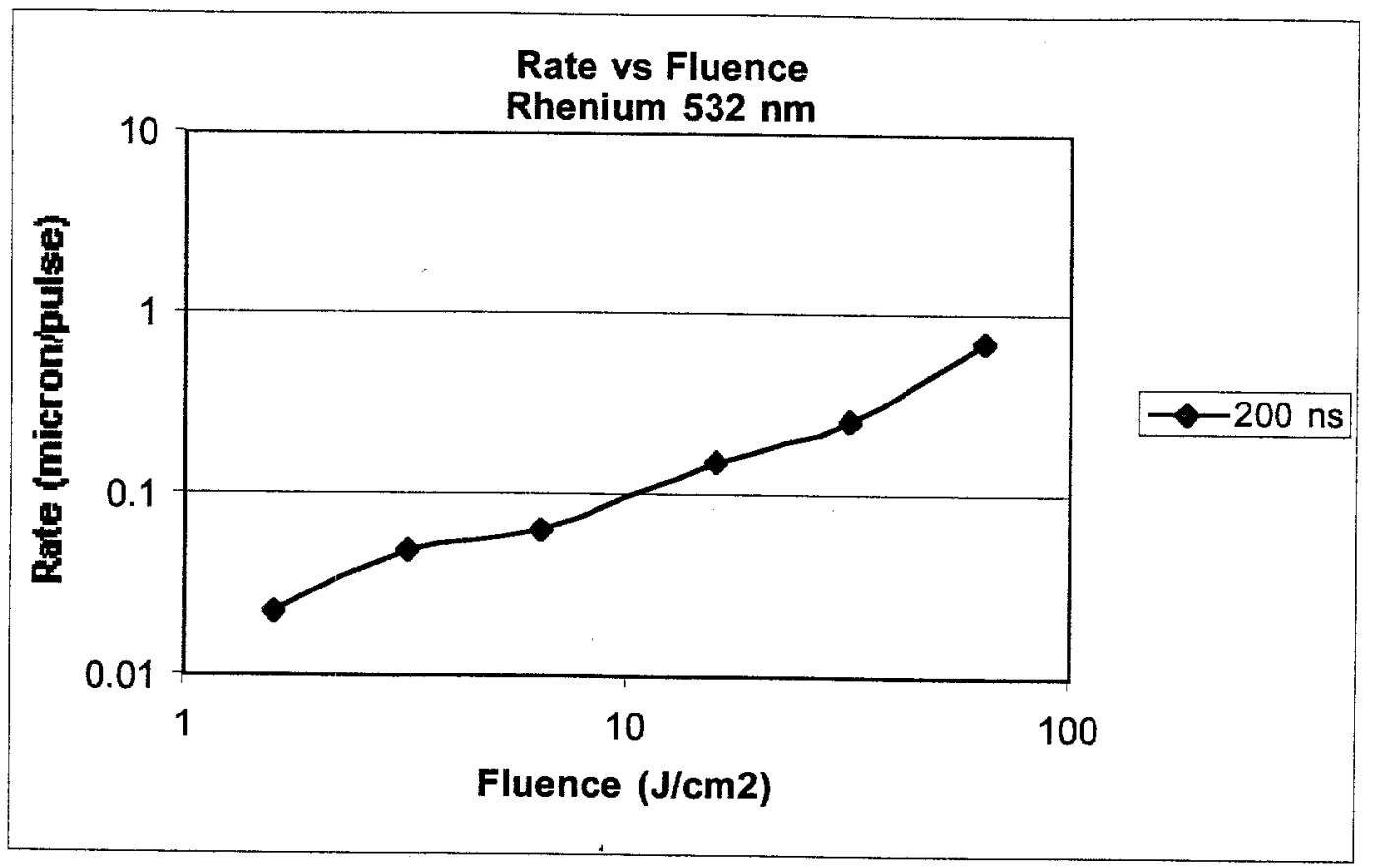




\section{Titanium}
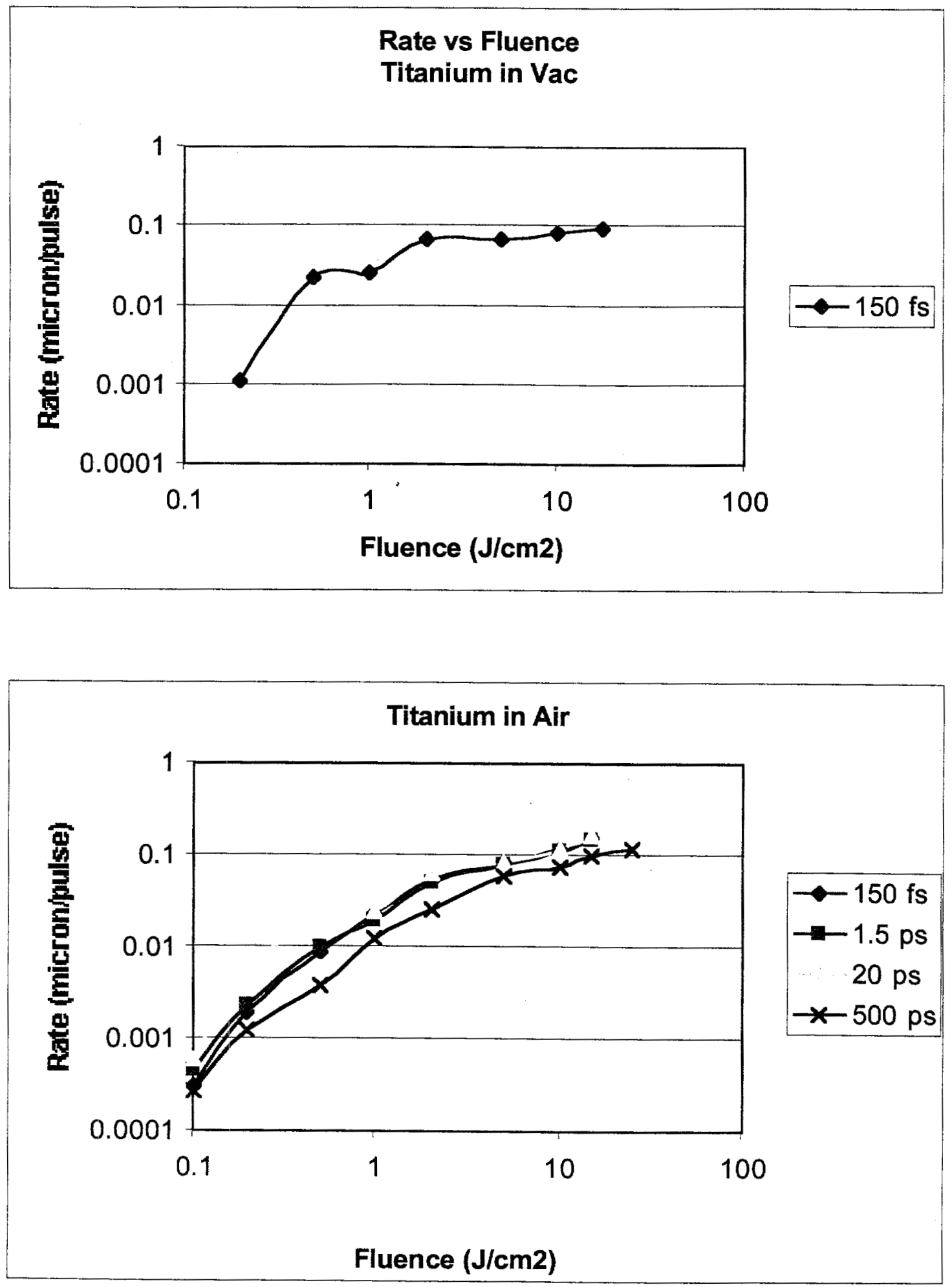

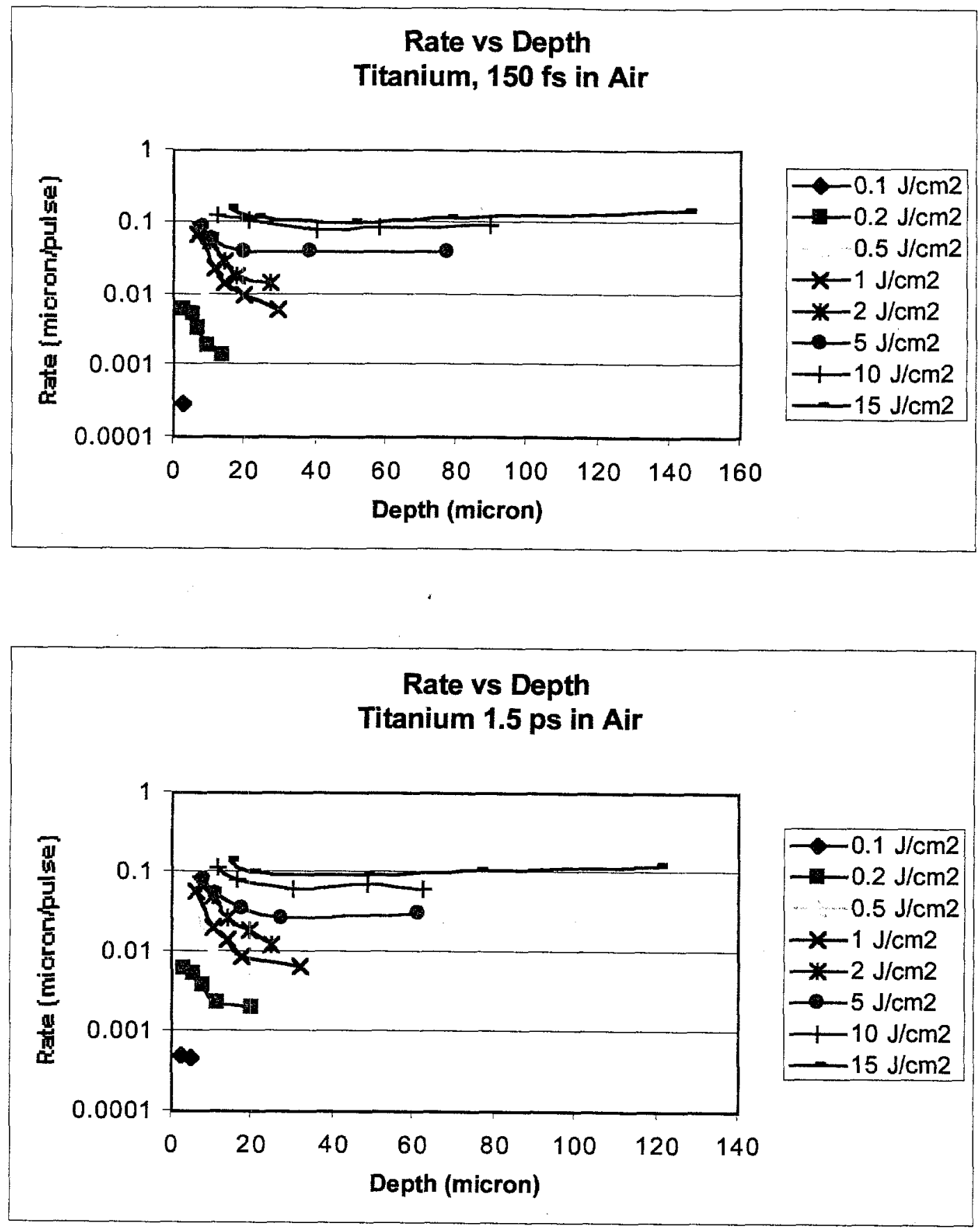

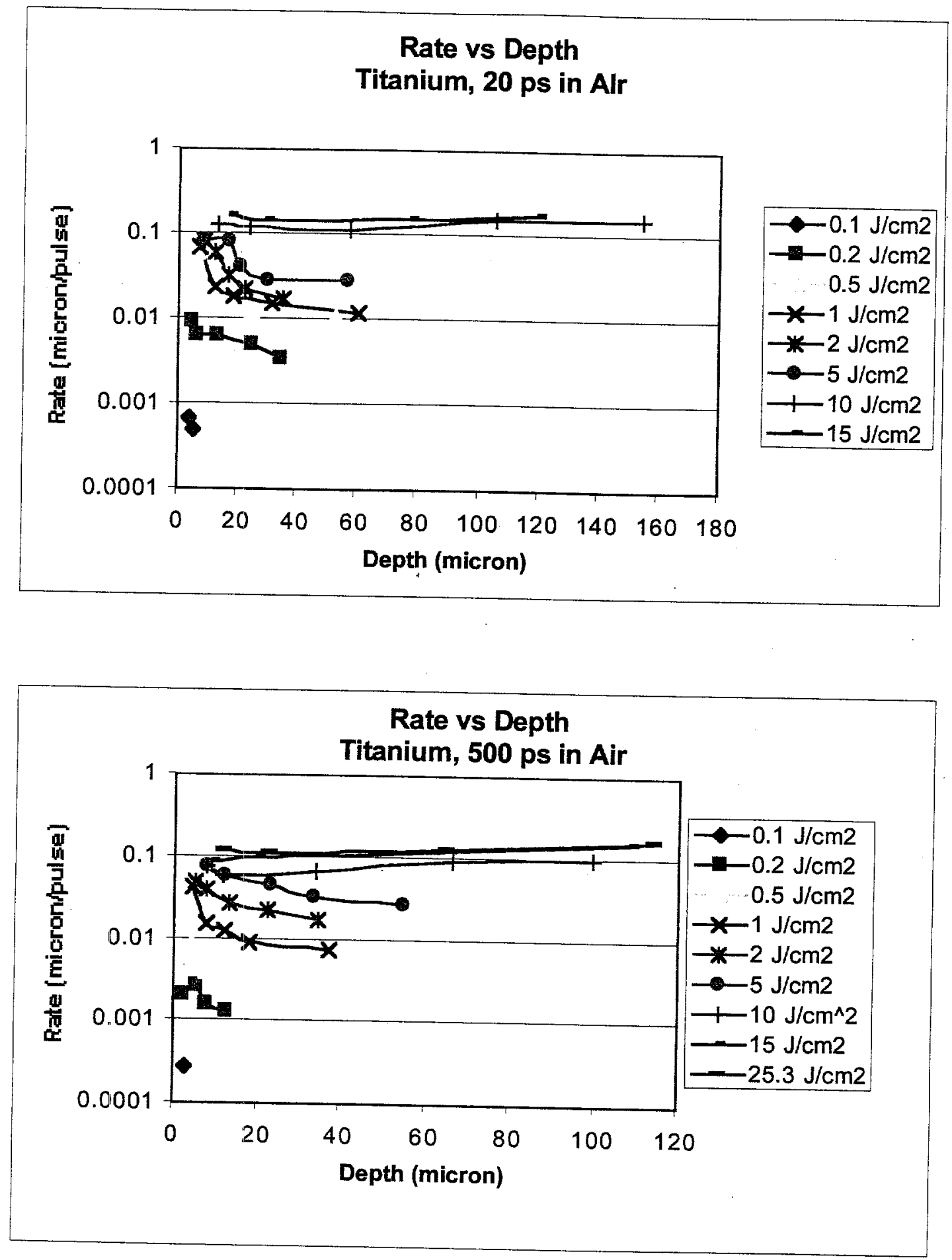

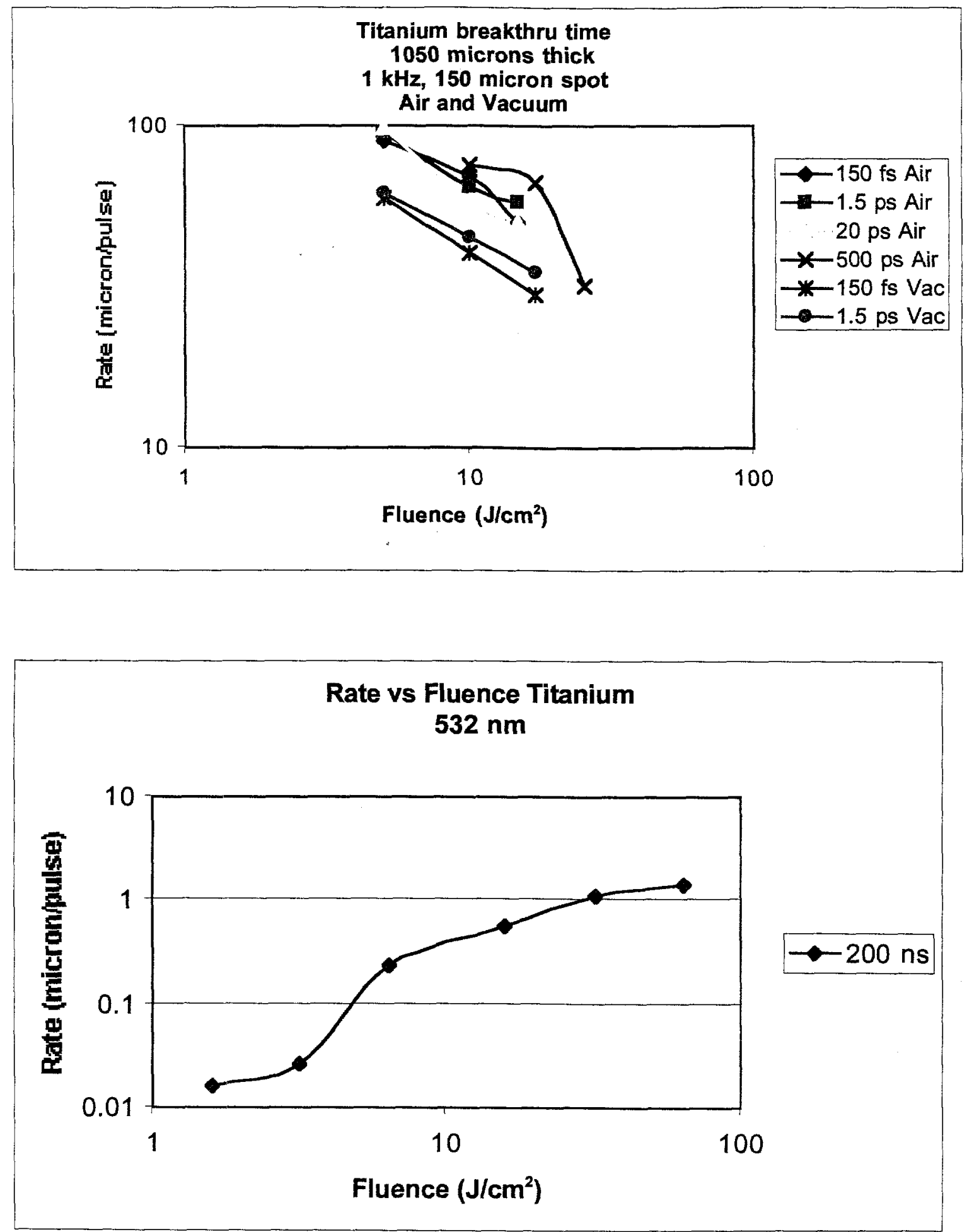


\section{Hastalloy X}
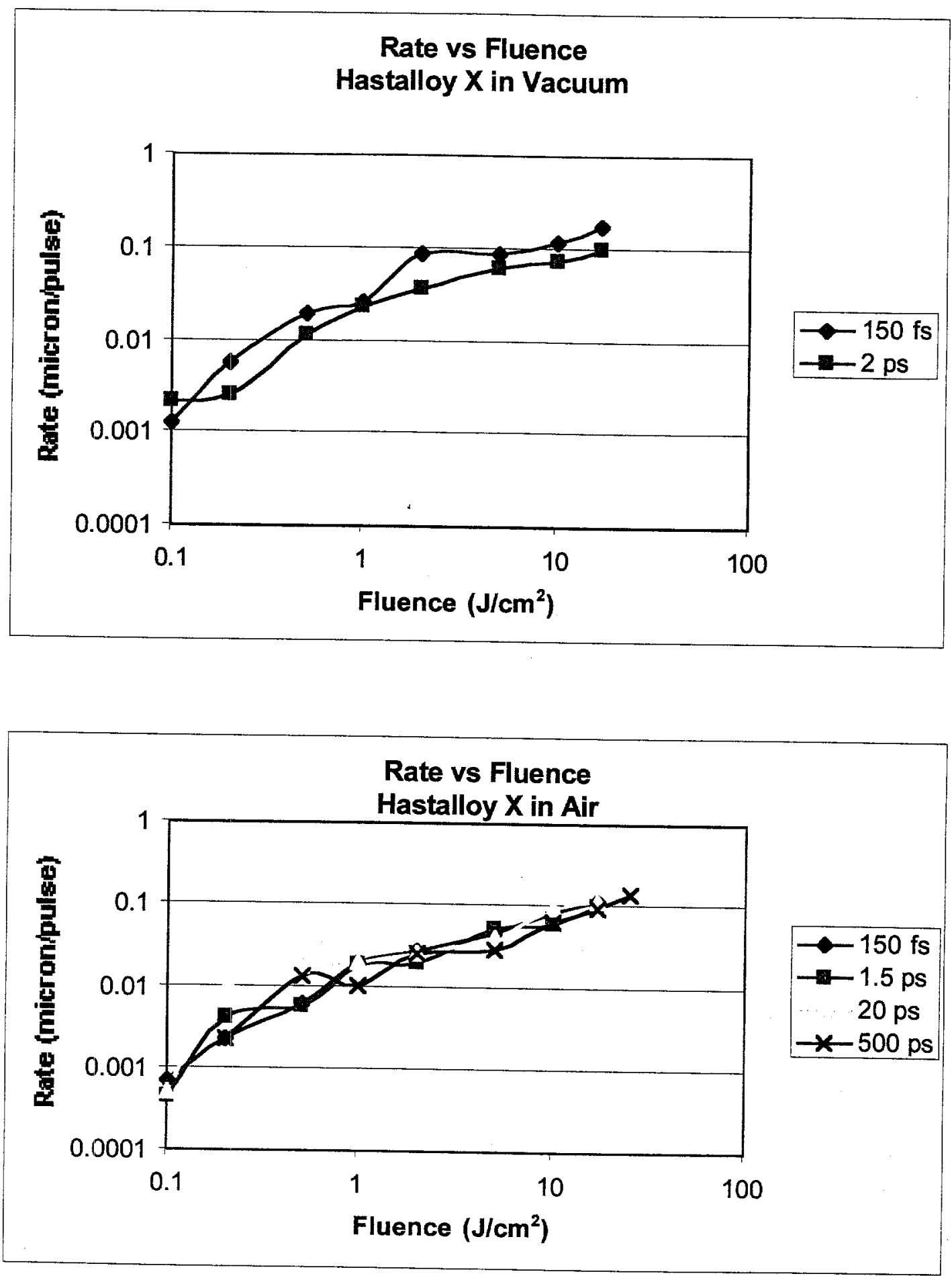

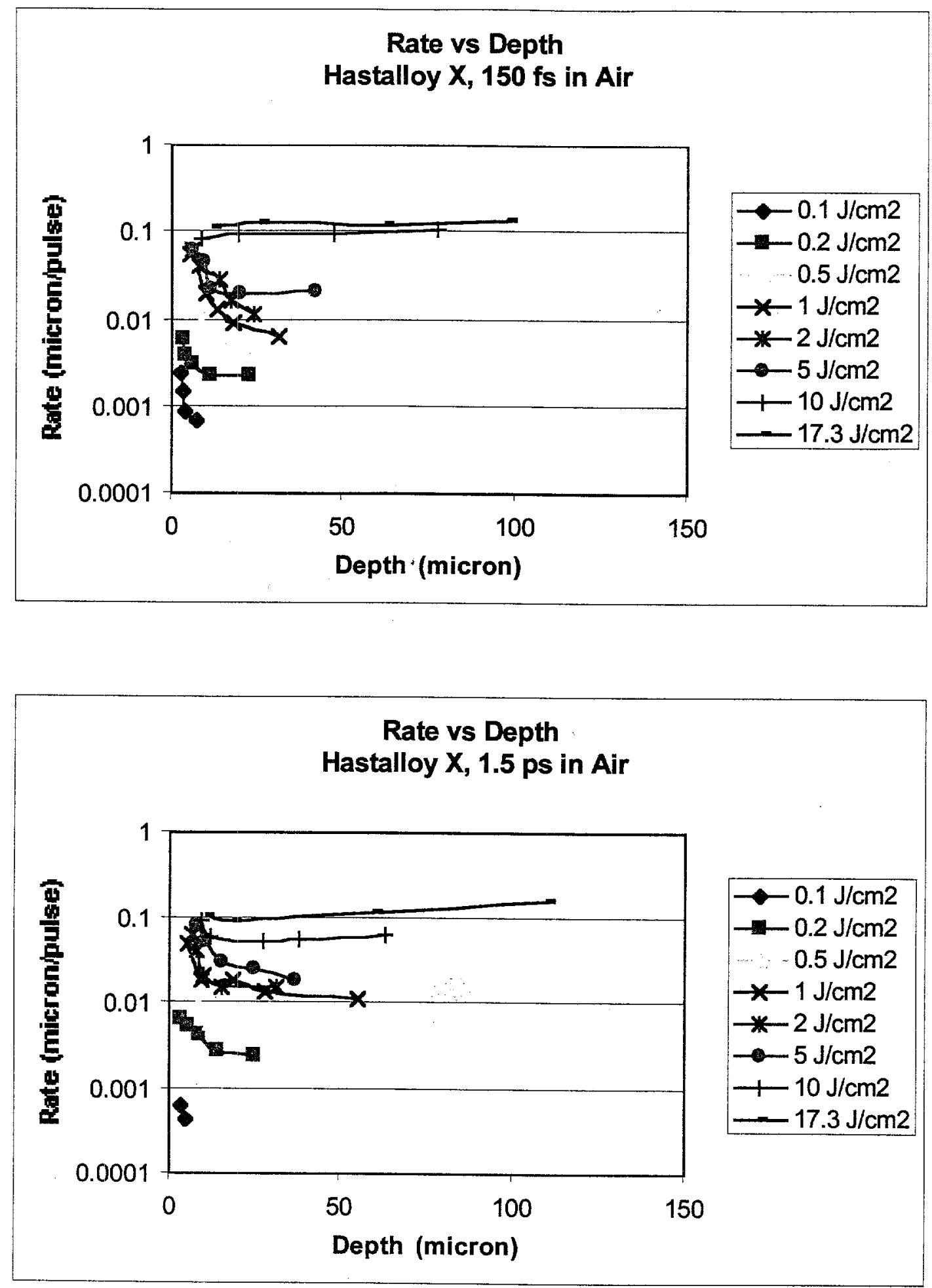

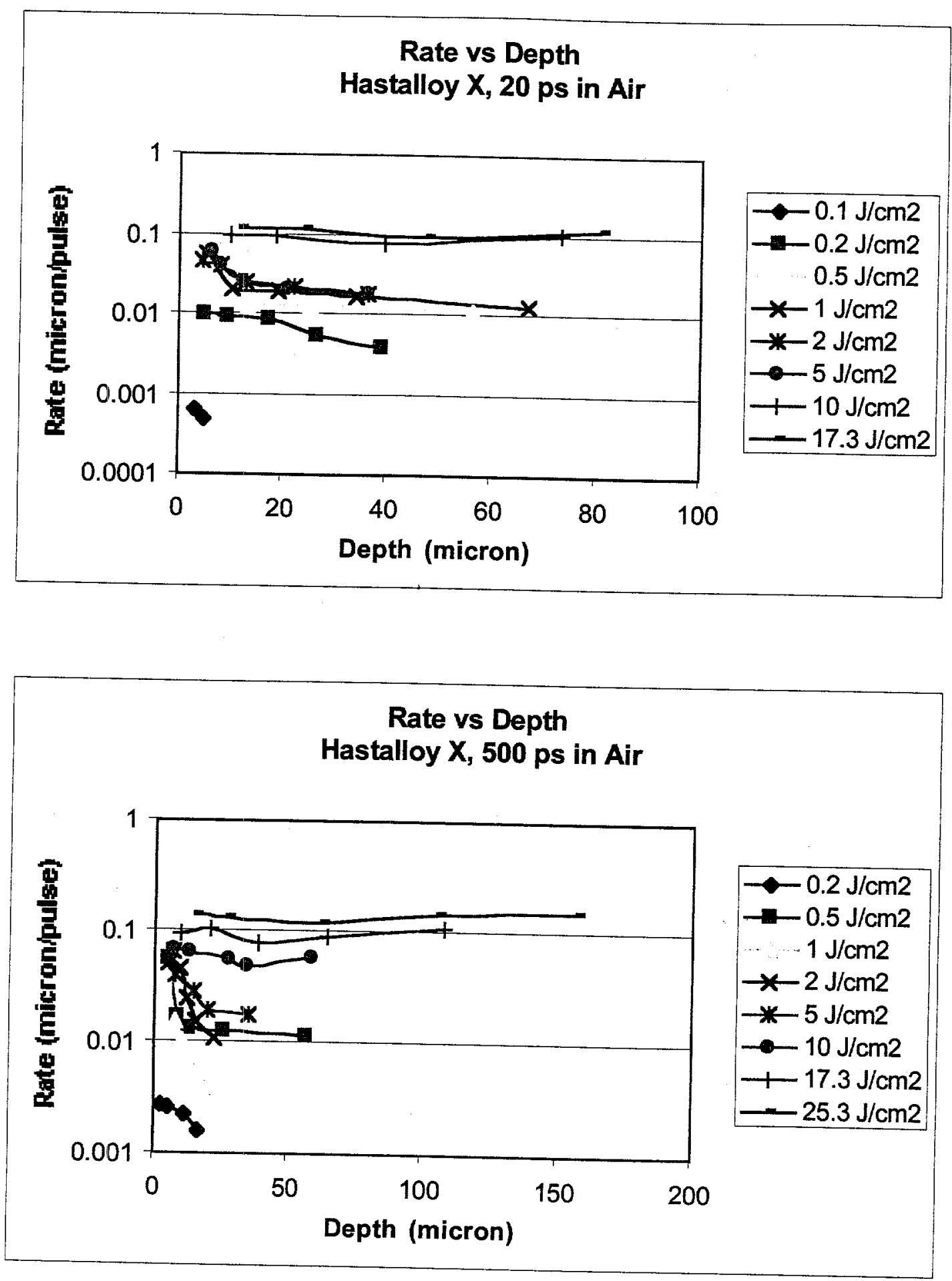

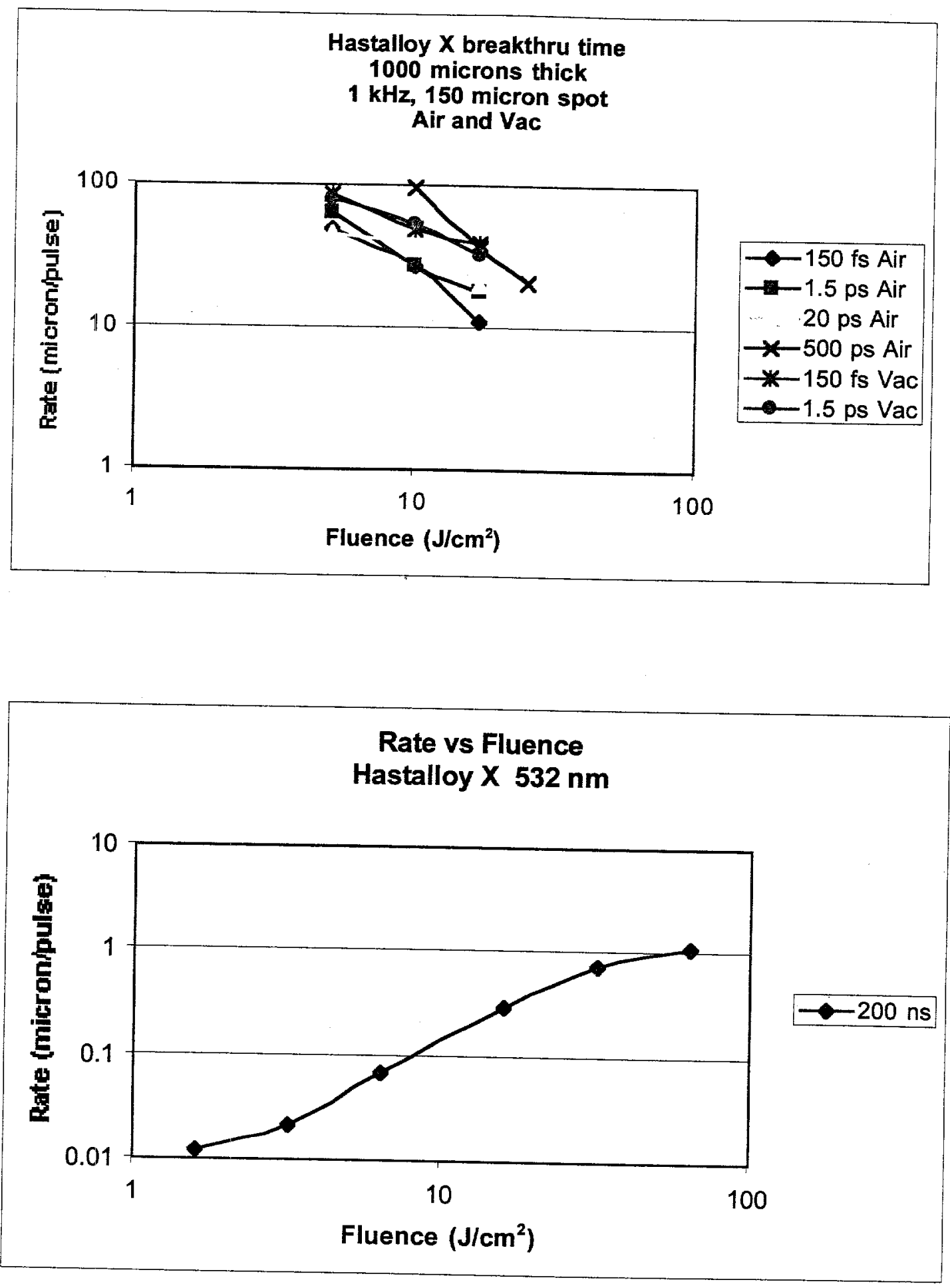

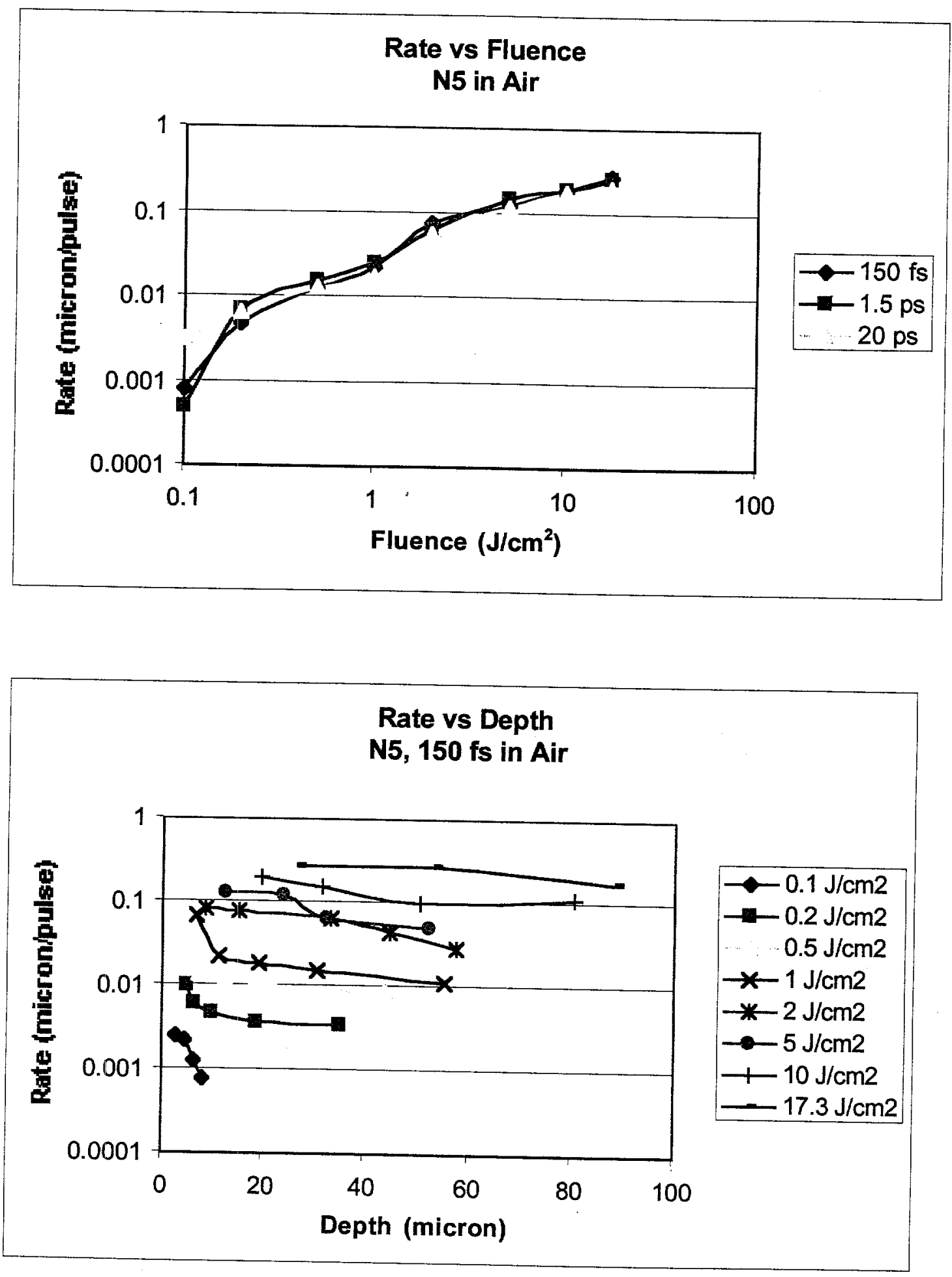

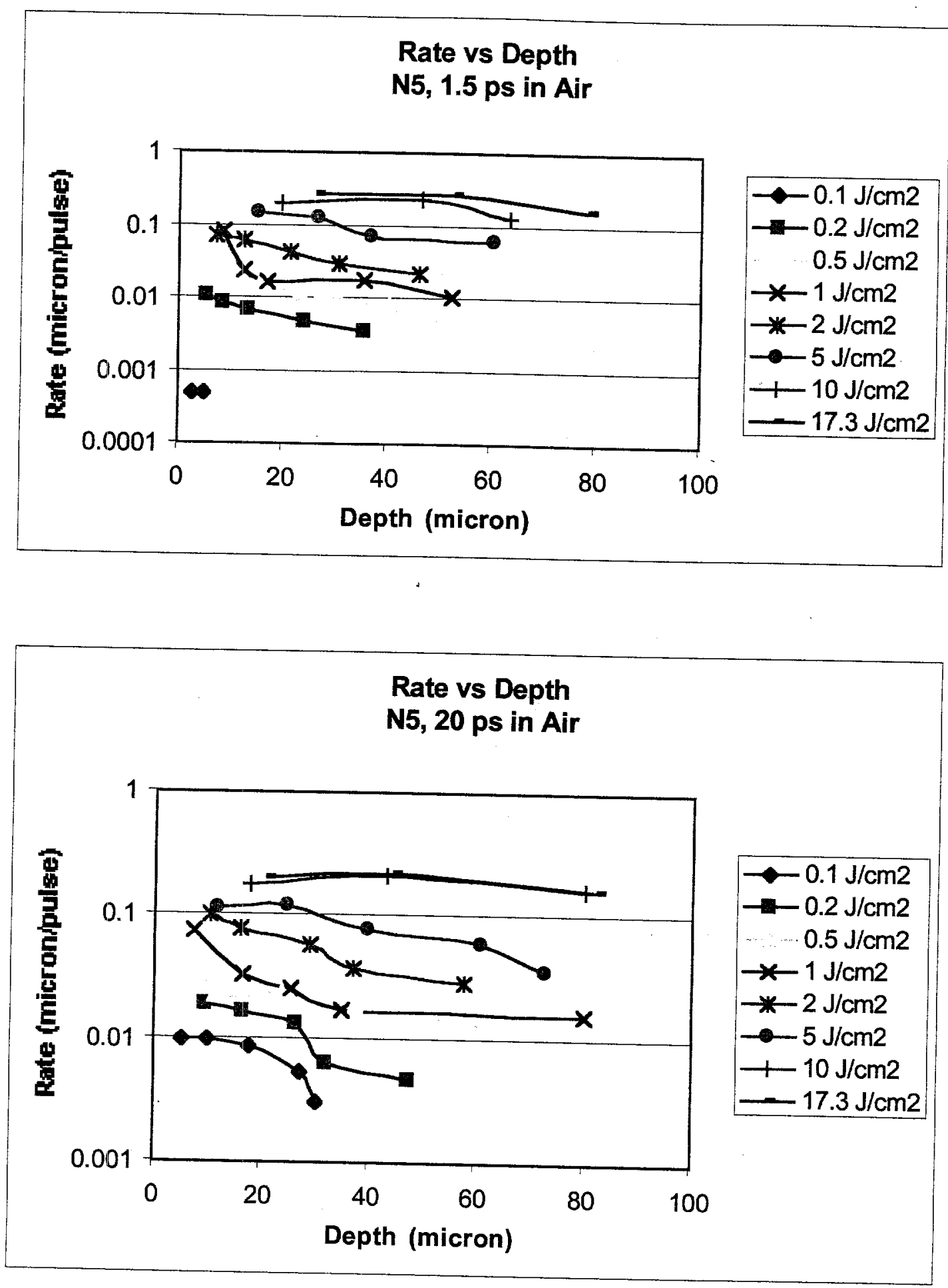


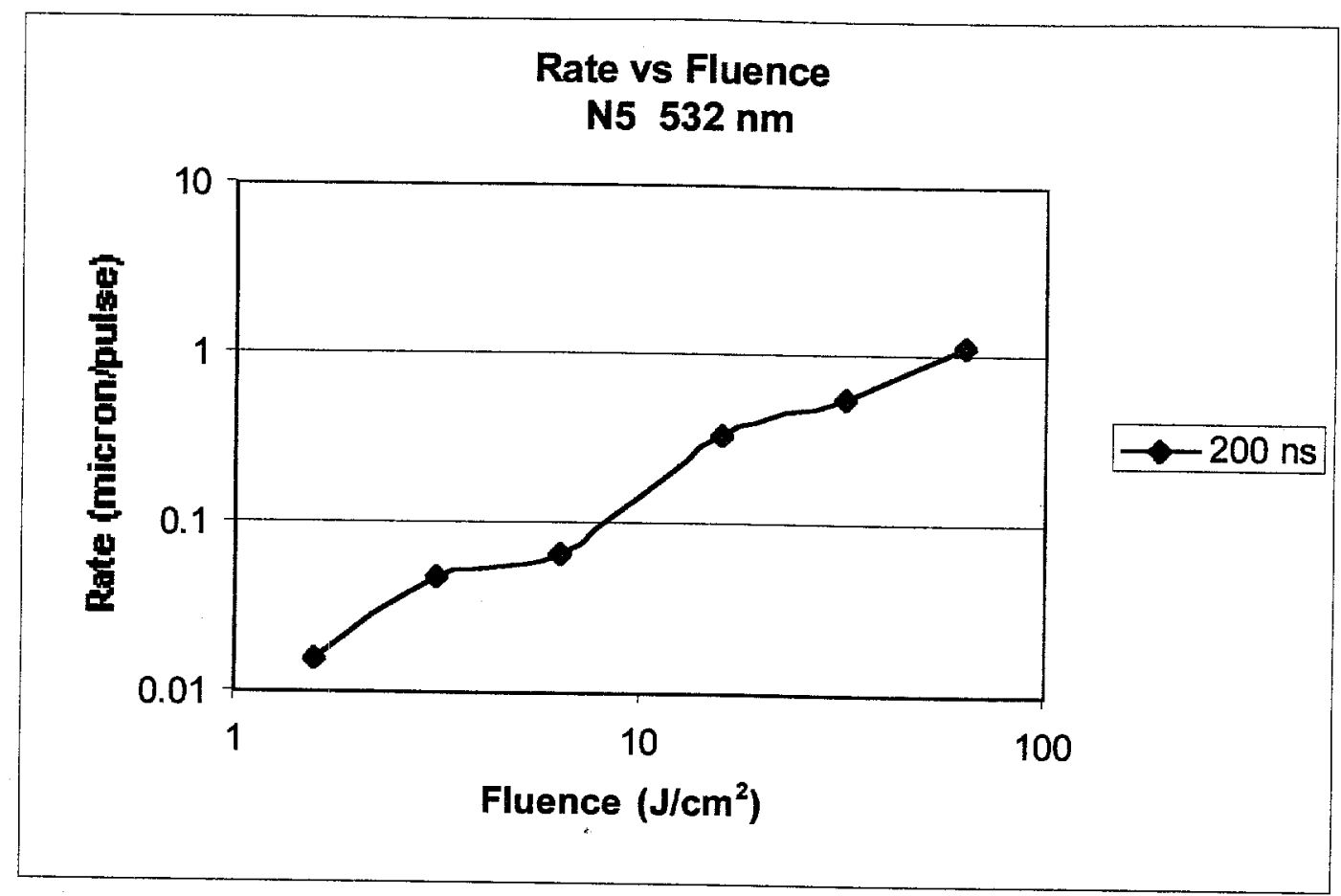




\section{Silicon Carbide}
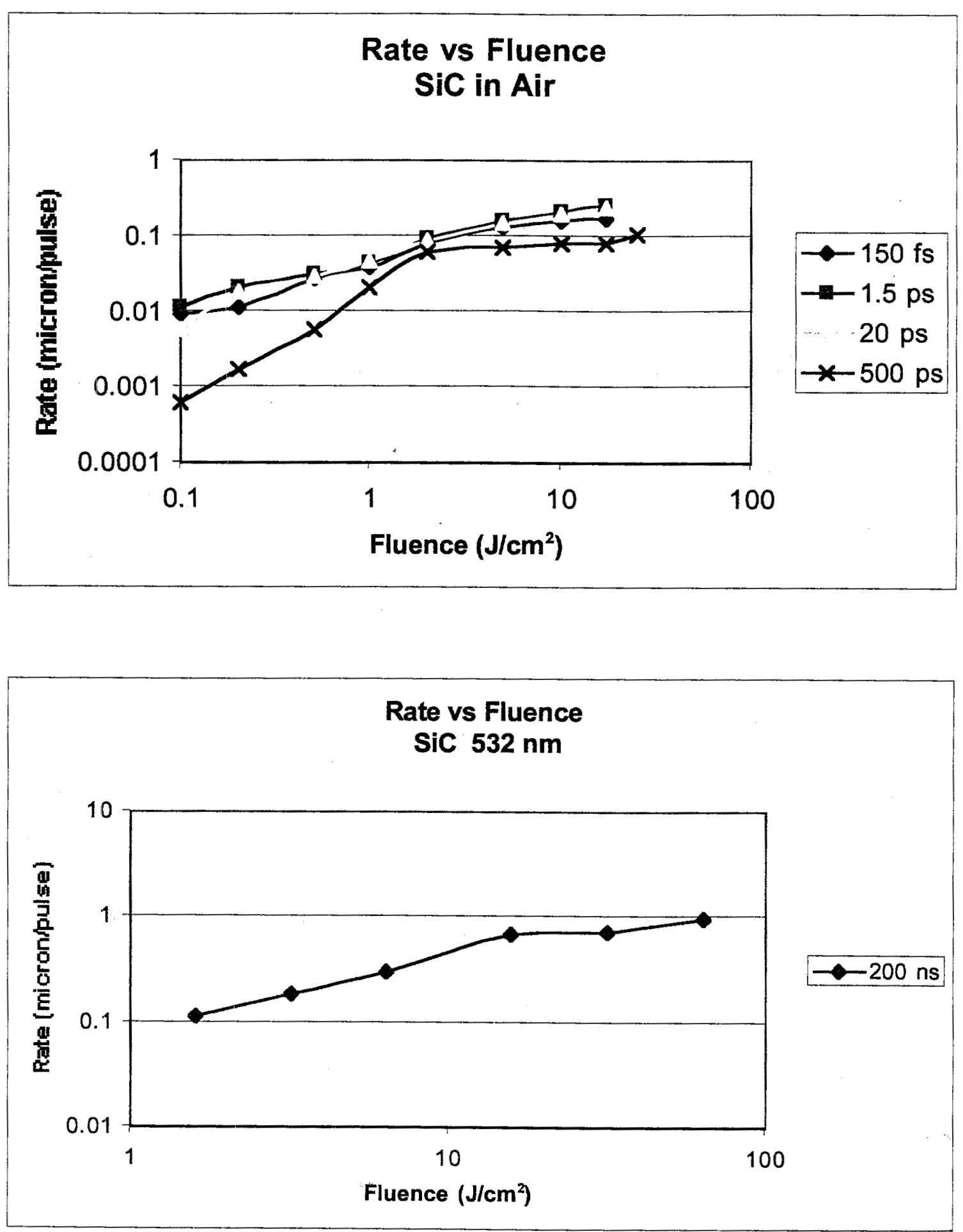

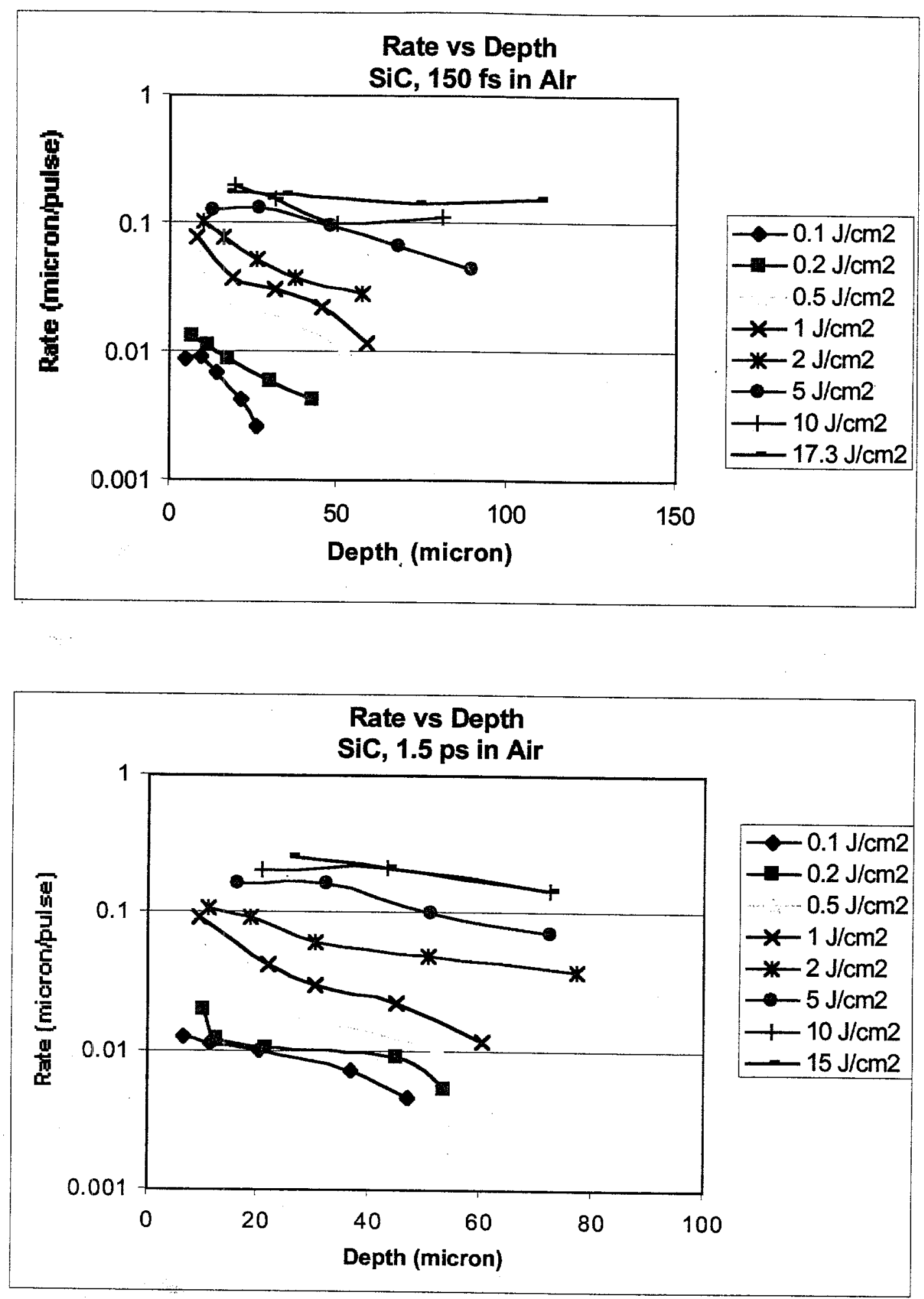

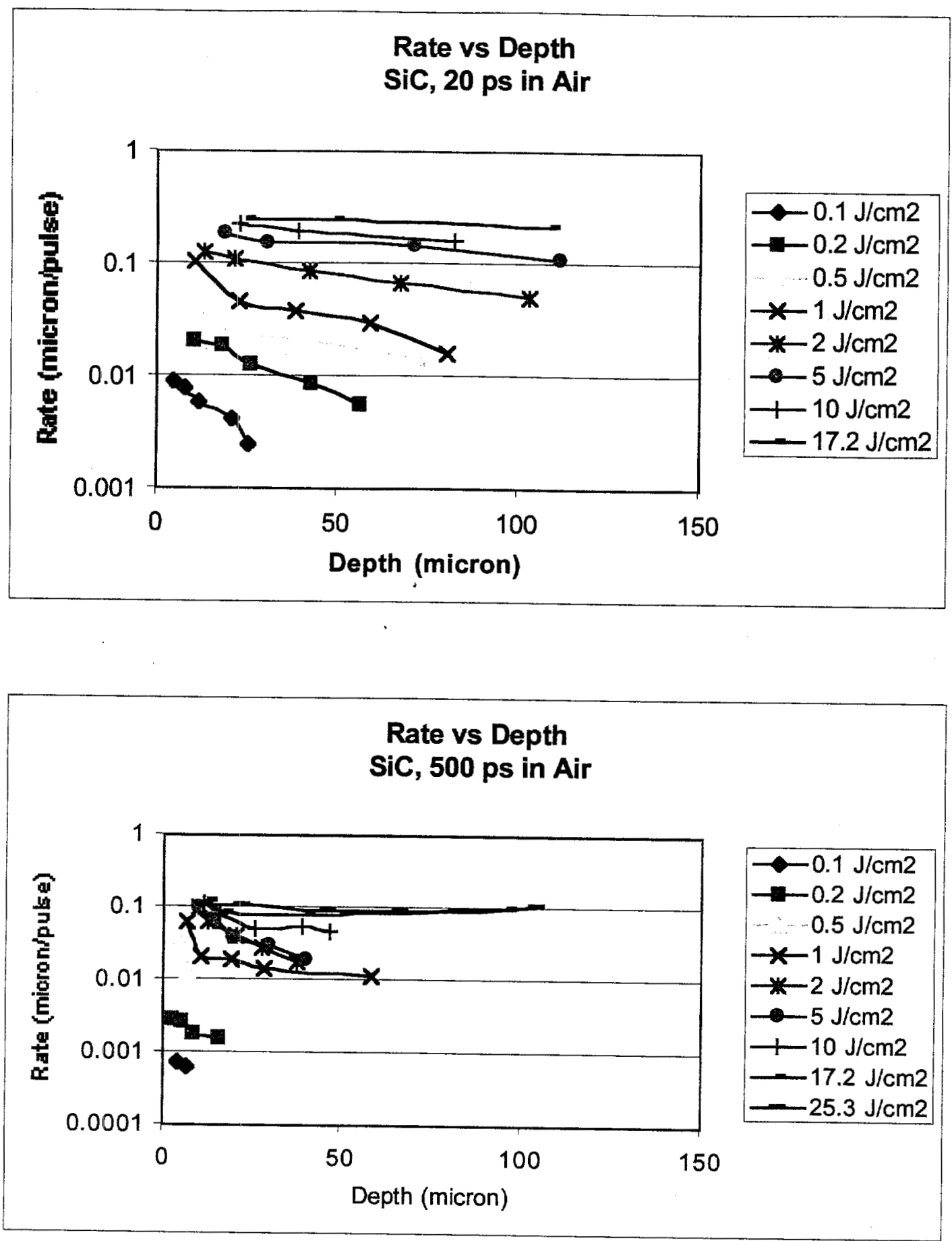


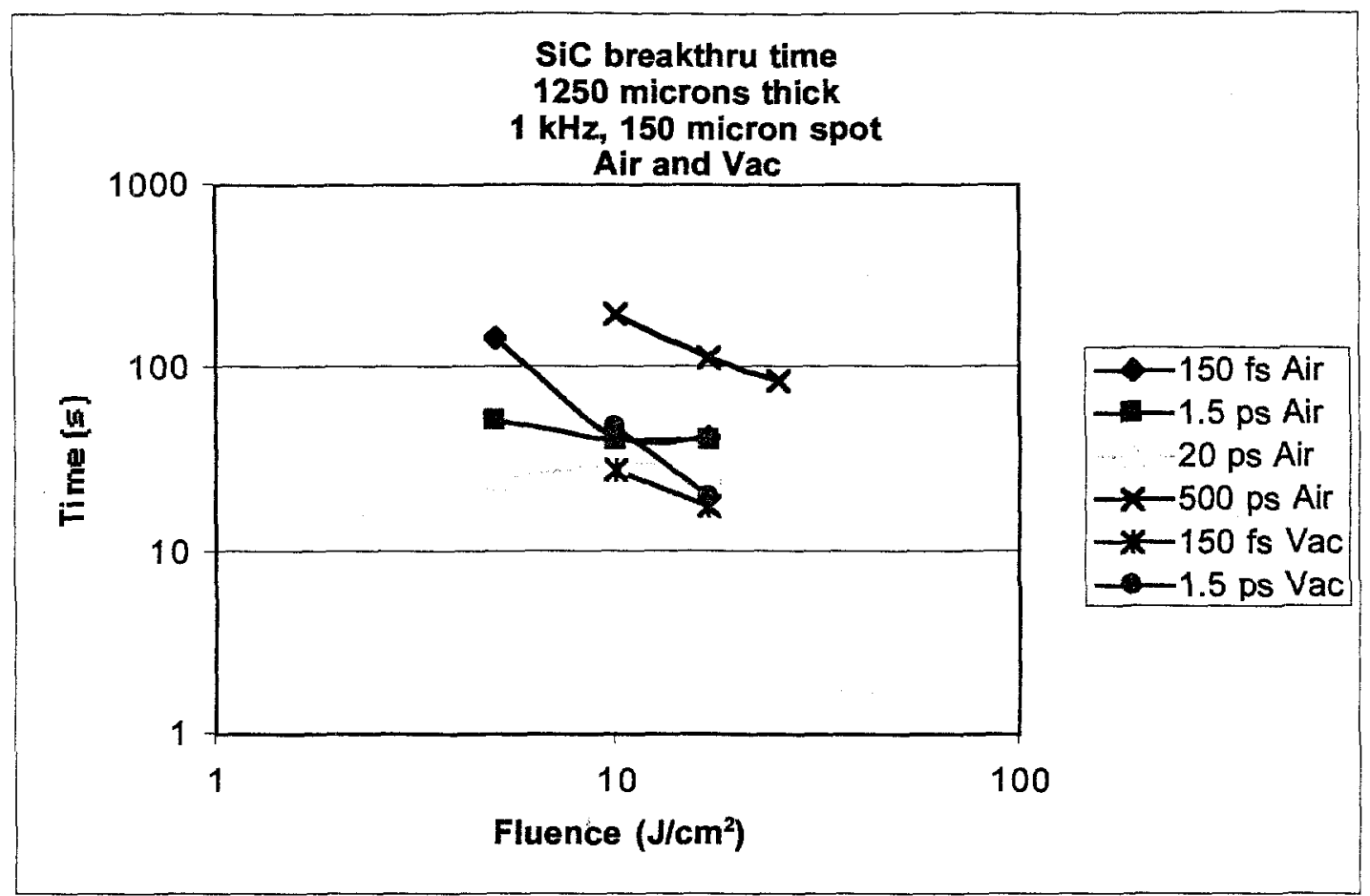




\section{Discussion}

We found that the laser pulse-width did not have any significant effect on initial ablation rate. There was also little noticeable difference in initial ablation rate while comparing air and vacuum. The shapes of the curves were similar and the rates were slightly lower in air. However, the effects of a vacuum environment were quite apparent when drilling through thick $(1 \mathrm{~mm})$ samples at high aspect ratios as discussed in a later section.

We found a strong dependence of ablation rate on depth of the hole. Channel formation and increasing roughness of the bottom of the hole with an increasing number of pulses can explain this reduction of ablation rate with depth of the hole.

At low fluences, we believe that increasing roughness with increasing number of pulses is one of the causes of the reduction of ablation rate. Also, as the angle of the walls of the hole increases, the rate will decrease due to the laser fluence on the walls dropping below ablation threshold. At high fluences, the rate decreases up to a certain depth and then increases again. This is explained by the formation of the central channel in the bottom of the hole that has a much faster ablation rate than the rest of the hole. This seems to occur at depths greater than $\mathbf{4 0}$ microns and at fluences greater than 5 $\mathrm{J} / \mathrm{cm}^{2}$.

Breakthrough times measured were generally shorter in vacuum than in air for most materials. This is due to channel formation as well as lack of laser-air interaction in a vacuum.

Below are tables of initial ablation rates at select pulse widths and fluences:

Rates at $150 \mathrm{fs}(810 \mathrm{~nm})$

\begin{tabular}{|c|c|c|c|c|}
\hline & \multicolumn{2}{|c|}{ Fluence $=1 \mathrm{~J} / \mathrm{cm}^{2}$} & \multicolumn{2}{|l|}{ Fluence $=10 \mathrm{~J} / \mathrm{cm}^{2}$} \\
\hline Material & Rate in Air & Rate in Vac & Rate in Air & Rate in Vac \\
\hline Stainless & $0.022 \mu \mathrm{m} /$ pulse & $0.025 \mu \mathrm{m} /$ pulse & $0.09875 \mu \mathrm{m} / \mathrm{pulse}$ & $0.098 \mu \mathrm{m} /$ pulse \\
\hline Rhenium & $0.018 \mu \mathrm{m} / \mathrm{pulse}$ & $0.019 \mu \mathrm{m} /$ pulse & $0.085 \mu \mathrm{m} / \mathrm{pulse}$ & $0.079 \mu \mathrm{m} /$ pulse \\
\hline Titanium & $0.023 \mu \mathrm{m} /$ pulse & $0.025 \mu \mathrm{m} /$ pulse & $0.12 \mu \mathrm{m} /$ pulse & $0.085 \mu \mathrm{m} /$ pulse \\
\hline N5 & $0.022 \mu \mathrm{m} /$ pulse & & $0.195 \mu \mathrm{m} / \mathrm{pulse}$ & \\
\hline Hastalloy X & $0.019 \mu \mathrm{m} /$ pulse & $0.026 \mu \mathrm{m} /$ pulse & $0.085 \mu \mathrm{m} /$ pulse & $0.12 \mu \mathrm{m} /$ pulse \\
\hline $\mathrm{SiC}$ & $0.038 \mu \mathrm{m} / \mathrm{pulse}$ & & $0.15625 \mu \mathrm{m} / \mathrm{pulse}$ & \\
\hline
\end{tabular}


Rates at $500 \mathrm{ps}(810 \mathrm{~nm})$

\begin{tabular}{|l|l|l|l|l|}
\hline & \multicolumn{2}{|c|}{ Fluence $=1 \mathrm{~J} / \mathrm{cm}^{2}$} & Fluence $=10 \mathrm{~J} / \mathrm{cm}^{2}$ & Rate in Vac \\
\hline Material & Rate in Air & Rate in Vac & Rate in Air & $0.11 \mu \mathrm{m} / \mathrm{pulse}$ \\
\hline Stainless & $0.0095 \mu \mathrm{m} / \mathrm{pulse}$ & $0.018 \mu \mathrm{m} / \mathrm{pulse}$ & $0.049 \mu \mathrm{m} / \mathrm{pulse}$ & \\
\hline Rhenium & $0.0059 \mu \mathrm{m} / \mathrm{pulse}$ & & $0.049 \mu \mathrm{m} / \mathrm{pulse}$ & \\
\hline Titanium & $0.012 \mu \mathrm{m} / \mathrm{pulse}$ & & $0.078 \mu \mathrm{m} / \mathrm{pulse}$ & \\
\hline Hastalloy X & $0.011 \mu \mathrm{m} / \mathrm{pulse}$ & & $0.066 \mu \mathrm{m} / \mathrm{pulse}$ & \\
\hline SiC & $0.021 \mu \mathrm{m} / \mathrm{pulse}$ & & $0.08 \mu \mathrm{m} / \mathrm{pulse}$ & \\
\hline
\end{tabular}

\section{Green Rates (532 nm)}

\begin{tabular}{|l|l|l|}
\hline & Fluence $=1.6 \mathrm{~J} / \mathrm{cm}^{2}$ & Fluence $=16 \mathrm{~J} / \mathrm{cm}^{2}$ \\
\hline Material & Rate & Rate \\
\hline Stainless & $0.028 \mu \mathrm{m} /$ pulse & $0.75 \mu \mathrm{m} /$ pulse \\
\hline Rhenium & $0.023 \mu \mathrm{m} /$ pulse & $0.16 \mu \mathrm{m} /$ pulse \\
\hline Titanium & $0.017 \mu \mathrm{m} /$ pulse & $0.58 \mu \mathrm{m} /$ pulse \\
\hline N5 & $0.016 \mu \mathrm{m} /$ pulse & $0.34 \mu \mathrm{m} /$ pulse \\
\hline Hastalloy X & $0.012 \mu \mathrm{m} /$ pulse & $0.3 \mu \mathrm{m} /$ pulse \\
\hline SiC & $0.12 \mu \mathrm{m} /$ pulse & $0.68 \mu \mathrm{m} /$ pulse \\
\hline
\end{tabular}

This work was performed under the auspices of the U.S. Department of Energy by the University of California, Lawrence Livermore National Laboratory under Contract No. W-7405-Eng-48. 